\title{
Cinema, educação e imaginários contemporâneos: estudos hermenêuticos sobre distopia, niilismo e afirmação nos filmes $O$ som ao redor, O cavalo de Turim e Sono de inverno
}

Rogério de Almeida ${ }^{1}$

\section{Resumo}

0 presente trabalho apresenta os resultados de pesquisa pós-doutoral ${ }^{2}$ que teve como objetivo estudar a relação entre cinema, educação e os imaginários contemporâneos da distopia, do niilismo e da afırmação por meio da investigação hermenêutica de três filmes da presente década: $O$ som ao redor (2012), do brasileiro Kleber Mendonça Filho; $O$ cavalo de Turim (2011), do húngaro Béla Tarr; e Sono de inverno (2014), do turco Nuri Bilge Ceylan. 0 artigo apresenta uma síntese da fundamentação educativa do cinema a partir de sete eixos - cognitivo, filosófico, estético, mítico, existencial, antropológico e poético -, justifica as opções metodológicas adotadas e a abordagem hermenêutico-simbólica, para então efetuar a análise dos referidos filmes em confrontação com os imaginários contemporâneos. Os resultados da pesquisa mostram que os três enfoques selecionados - distopia, niilismo e afirmação -, embora distintos entre si, não aparecem isoladamente nos filmes, mas matizados. Assim, $O$ som ao redor não é puramente distópico, mas, em certa medida, também niilista; N'O cavalo de Turim, o imaginário niilista é acompanhado de certo grau de afırmação; e Sono de inverno só atinge a afırmação depois de percorrer degraus niilistas. Como conclusão, é possível sustentar que o contemporâneo se apresenta multifacetado, espaço de tensão de forças imaginário-discursivas que disputam uma imagem de mundo.

\section{Palavras-chave}

Cinema e educação - Imaginários contemporâneos - Distopia - Niilismo - Afırmação.

\section{Cinema, education, and contemporary imaginaries: hermeneutic studies on dystopia, nihilism, and affirmation in the films $\mathrm{O}$ som ao redor, The Turin Horse and Winter sleep}

\footnotetext{
1- Universidade de São Paulo, São Paulo, SP, Brasil. Contato: rogerioa@usp.br.

2 - Realizada no Instituto de Educação da Universidade do Minho (Braga, Portugal), sob a supervisão do Prof. Dr. Alberto Filipe Araújo, no período de julho de 2016 a janeiro de 2017, com bolsa de pesquisa no exterior concedida pela Fundação de Amparo à Pesquisa do Estado de São Paulo (FAPESP).
} 


\section{Abstract}

This article presents the results of the postdoctoral research whose aims was to study the relation between cinema, education, and the contemporary imaginaries of dystopia, nihilism and affirmation through the hermeneutic investigation of three films released in this decade: 0 Som ao Redor (Neighboring Sounds, 2012) by Brazilian filmmaker Kleber Mendonça Filho, The Turin Horse (2011) by Hungarian director Béla Tarr and Winter Sleep (2014) by Turkish filmmaker Nuri Bilge Ceylan. This work presents a synthesis of the educative grounds of cinema in seven axes - cognitive, philosophical, aesthetic, mythical, existential, anthropological and poetic -, justifies the methodological options adopted and the hermeneutic-symbolic approach in order to carry out the analysis of the films in confrontation with contemporary imaginaries. The results of the research show that the selected approaches - dystopia, nihilism and affirmation - do not appear isolated in the films but are nuanced. Neighboring Sounds is not purely dystopic but rather a little nihilistic. In The Turin Horse the nihilistic imaginary is accompanied by a certain degree of affirmation. Winter Sleep only reaches the affirmation after traveling nihilistic steps. The conclusion is that the contemporary is multifaceted, a space of tension of imaginarydiscursive forces that compete for an image of the world.

\section{Keywords}

Cinema and education - Contemporary imaginaries - Dystopia - Nihilism - Affirmation.

\section{Pressupostos fundantes da relação entre cinema, educação e imaginário}

0 desafio de estudar a relação entre cinema, educação e os imaginários contemporâneos me conduziu inicialmente a um rol de filmes - grande parte produzida no presente século - que estimularam a reflexão sobre as disputas discursivo-simbólicas pela formulação de uma imagem de mundo, no sentido dado pela hermenêutica ricoeuriana para a qual o texto é uma proposição de mundo com a qual posso dialogar a partir dos meus próprios mundos possíveis (RICOEUR, 2008). Esses filmes foram se agrupando em três grandes imaginários, ainda que não únicos, cujas proposições de mundo remetiam ao universo simbólico da distopia, do niilismo e da afırmação. Para uma análise aprofundada, optei por selecionar um filme para cada um dos três imaginários escolhidos, de modo que o conjunto permitisse expor, analisar e diferenciar, com o crivo do contemporâneo, a distopia, o niilismo e a afirmação.

Os filmes eleitos foram $O$ som ao redor (2012), de Kleber Mendonça Filho; $O$ cavalo de Turim (2011), de Béla Tarr; e Sono de inverno (2014), de Nuri Bilge Ceylan. Os critérios utilizados para a seleção foram: relevância cinematográfica, repercussão crítica, pertinência temática, recorte temporal e heterogeneidade. Não se buscou uma análise política, sociológica, ideológica ou crítica dos filmes em questão, mas uma abordagem 
hermenêutico-simbólica sobre o modo como cada película interpela e interpreta o contemporâneo.

Na perspectiva hermenêutica aqui adotada, considera-se que as obras cinematográficas propõem um mundo, um mundo cinematográfico, ou seja, um mundo que seja próprio da obra fílmica, mas que não evita o diálogo com o mundo social, cotidiano, vivido no dia a dia. "Tal como todas as outras formas simbólicas [filosofia, ciência, religião], a arte não é uma simples reprodução de uma realidade dada, pronta. É um dos meios que levam a uma visão objetiva das coisas e da vida humana” (CASSIRER, 1994, p. 234).

Portanto, ao problematizar nosso olhar sobre o mundo, os outros e nós mesmos, o cinema, principalmente quando compreendido em sua faceta educativa, propicia o efeito de nos colocar diante de uma dada realidade e simultaneamente à distância. Participamos sem compromisso de outras vidas e realidades, de outros modos de ver e viver, fazendo circular sentidos, configurando imaginários e organizando forças discursivas, como as da distopia, do niilismo e da afırmação.

A narrativa cinematográfica dos filmes de ficção constitui-se como uma paisagem aberta, pode ser considerada discurso, forma de conhecimento, texto a ser interpelado, imaginário que organiza simbolicamente a realidade. Enfim, ela é, a um só tempo, obra de cultura, de arte, mas também produto mercadológico e prática social; alimenta tanto a fruição estética quanto o pensamento analítico e encerra, em certo sentido, uma pedagogia, pois seu imaginário exerce uma pressão pedagógica (DURAND, 1997) que produz sentidos, multiplica realidades e dissemina modos de viver.

0 cinema fundamenta-se educacionalmente não por ser um conjunto de saberes ou uma ferramenta ilustrativa e complementar dos conteúdos curriculares, mas justamente por se realizar processualmente como relação entre imagens (montagem) que engendra sentidos tanto estética quanto cognitivamente; dessa operação resultam narrativas impregnadas de sentidos (literais, metafóricos, simbólicos, alegóricos etc.) que podem ser pensados, sentidos, interpelados, interpretados, compreendidos ou mesmo suspendidos (ALMEIDA, 2014).

Não se trata, entretanto, de reduzir o cinema à sua dimensão narrativa e aos sentidos que evoca e provoca, mas de tomá-los como ponto de partida para a experiência possível na fruição de obras cinematográficas. E essa experiência ramifica-se em perspectivas de abordagens, em fundamentos educativos que atestam o potencial formativo do cinema.

$\mathrm{Na}$ perspectiva de trabalho aqui adotada, que se importa com a experiência cinematográfica - relação entre o fílmico (texto), o extrafílmico (contexto) e o espectador -, circulam sete fundamentos que facultam e matizam essa experiência: cognitivo, filosófico, estético, mítico, existencial, antropológico e poético (ALMEIDA, 2017). Como o objetivo deste artigo não é estudar esses fundamentos, mas referenciá-los como base teórica que justifica a aproximação entre cinema e educação na investigação sobre os imaginários contemporâneos, apresento-os resumidamente.

0 fundamento cognitivo desloca o foco da obra para o espectador, por entender que sua participação na construção da experiência fílmica é ativa, o que David Bordwell (1996, p. 31) chama de "processo perceptual-cognitivo dinâmico". Assistir a um filme faz convergir percepção e cognição em busca de comprovação das hipóteses elaboradas com 
os dados fílmicos, de modo que a interpretação é construída, desconstruída e reconstruída diversas vezes durante a experiência fílmica.

A atividade cognitiva pode facultar o fundamento filosófico, pelo qual se reconhece que o cinema pensa (CABRERA, 2006), que os diretores "pensam com imagens-movimento e com imagens-tempo, em vez de conceitos” (DELEUZE, 1985, p. 8), que o cinema cria novas ideias sobre o que é uma ideia (BADIOU, 2004), que o cinema propõe uma outra cena da realidade (ROSSET, 2010), tendo, portanto, o potencial de alimentar a reflexão sobre o mundo, a vida, o amor, a morte, as relações, o conhecimento, a política, a sociedade, o passado, o futuro - enfim, temas caros à filosofia.

No entanto, o cinema não se detém nos aspectos cognitivo-intelectuais do humano, mas o toca pela emoção, pela sensação, pelo gosto, o que põe em cena o fundamento estético. Assim, na contemporaneidade, a experiência estética se alarga, desterritorializa-se, desloca-se da arte para a vida: "o alargamento da experiência artística, interessada na transformação dos processos de arte em sensações de vida, permite que se pense na possibilidade de se fundar uma estética generalizada" (FAVARETTO, 2011, p. 108). 0 cinema dialoga, portanto, com os modos de vida, com a arte de viver.

Outro fundamento educativo do cinema é o mítico, pois, concretamente, a fabulação cinematográfica atualiza os mitos que sempre estiveram presentes na mediação simbólica, dinâmica e narrativa do homem com o mundo. E se, no cinema, muitas histórias se repetem, é porque as mitologias "são relativamente pobres e só têm um número restrito de elementos míticos que se chamam 'mitemas' e combinações desses elementos em número relativamente simples” (DURAND, 1981, p. 74). Não obstante, a engenhosidade humana inventa novos modos de contar as velhas histórias, e o cinema, como uma máquina de mitos, exerce exatamente as mesmas funções que Campbell (2010) identifica na mitologia: reconcilia a consciência com o mistério da existência, interpreta o mundo, lida com a ordem moral e auxilia na busca de congruência entre o indivíduo e sua cultura.

0 quinto fundamento é o existencial, a condição reflexiva da consciência humana, consciente de sua própria consciência. O cinema é como um sonho acordado, um agenciador de devaneios - "vivemos o cinema dentro de um estado de dupla consciência" (MORIN, 2014, p. 15) -; ao nos percebermos existindo, percebemos a existência do outro, o outro do cinema, mas também o outro do mundo.

Essa consciência de si e do outro, dado profundamente humano, leva-nos ao próximo fundamento, o antropológico. 0 cinema é difusor de culturas, pois põe em cena não só modos de vida, mas seus aspectos problemáticos e simbólicos, de nossa e de outras culturas. Pelo cinema pode-se registrar, como o faria um etnógrafo, a vida de um esquimó ou de um executivo de Wall Street, sem a preocupação com os fatos verídicos, mas com a verossimilhança disseminadora de imaginários: "o imaginário estético, como todo imaginário, é o reino das carências e aspirações do homem encarnadas e colocadas em situação, tratadas no âmbito de uma ficção” (MORIN, 2014, p. 124).

0 sétimo fundamento expressa-se pelo estado poético, estado de arrebatamento ou, como pontuou Merleau-Ponty (1983, p. 116), um "modo peculiar de estar no mundo, de lidar com as coisas e com os seus semelhantes”. Assim, somos afetados poeticamente pelo cinema, no sentido em que Spinoza (2009, p. 98) compreende afeto: "afecções do corpo 
pelas quais sua potência de agir é aumentada ou diminuída, estimulada ou refreada”. Tal ideia é também partilhada por Nietzsche e sua fisiologia aplicada, que considera que os estados estéticos promovidos pelas obras são mais ou menos úteis ao desenvolvimento e à intensificação da vida (BENÍTEZ, 2012). Como assinala Bachelard (1971, p. 132), "assim que um poeta escolheu seu objeto, o próprio objeto muda de ser. É promovido à condição de poético".

Dados os fundamentos educativos do cinema, compreendidos como efeitos cognitivo-sensório-estéticos promovidos no espectador de modo a intensificar ou atenuar sua predisposição a pensar, sentir e refletir, é possivel inferir que há uma interação entre as fábulas cinematográficas e as leituras de mundo, de modo que aquelas contaminam estas e vice-versa. Dito de outro modo, a intepretação de narrativas fílmicas projeta "proposições de mundo" (RICOEUR, 2008, p. 66) que dialogam com o modo como lemos e interpretamos o mundo em que vivemos.

É com esses pressupostos e essa base que chegamos à hipótese de que podemos compreender, por meio da arte cinematográfica, o contemporâneo, que não se reduz à mera localização temporal, mas expressa-se como espaço de tensão de forças imaginário-discursivas que pleiteiam uma imagem do mundo: distópica, niilista e afirmativa.

\section{A distopia encarnada no presente: $O$ som ao redor}

Admirável mundo novo, de Aldous Huxley, foi publicado em 1932 e apresenta de maneira distópica uma sociedade regulada bio-psico-ideologicamente para o e pelo produtivismo científico-racionalista, na qual, apesar da felicidade geral, as pessoas vivem em estado de demência. 1984, de George Orwell, foi publicado em 1949 e também de maneira distópica apresenta uma sociedade totalitária repressora de qualquer pensamento contrário ao regime, encarnado na figura televisual e onipresente do Grande Irmão. Em 1953, Ray Bradbury publica Fahrenheit 451, título que faz alusão à temperatura em que os papéis queimam; a obra acompanha as transformações de Guy Montag de bombeiro incinerador de livros a homem-livro, cuja missão é preservar os livros na memória, já que estes, assim como as opiniões próprias e o pensamento crítico, foram proibidos naquela sociedade. Os três livros, cujas histórias foram apresentadas também no cinema, apresentam narrativas distópicas cruciais para a compreensão do século XX e imbricam-se diretamente à noção de utopia.

Como definiu Boaventura Souza Santos (apud ARAÚJO, 2016, p. 123), “a utopia é a metáfora de uma hipercarência formulada ao nível a que não pode ser satisfeita, [pelo que] o que é importante nela não é o que diz sobre o futuro, mas a arqueologia virtual do presente que a torna possível", definição que pode ser revertida para a distopia sem nenhum prejuízo de alcance e precisão, com a única distinção recaindo sobre o termo hipercarência, que requer ser substituído por hipertemor. Pois, assim como a utopia, a distopia também não concretiza no tempo os temores com os quais nasceu; e, assim como a utopia, também é reveladora da arqueologia virtual do presente. Utopia e distopia são indissociáveis, pois se a primeira é a expectativa de realização positiva de algo que se 
almeja, a segunda é a advertência de uma possível concretização negativa do que não se deseja. Utopia é sonho; distopia, pesadelo.

\begin{abstract}
Em todo o caso, a utopia está associada ao desejo de um mundo melhor e à necessidade de o construir na sociedade dos viventes, necessidade essa que a modernidade assume como projeto [...]. Acompanhando o percurso da produção utópica desde que Tomás More criou o nome para este gênero filosófico-literário até a atualidade, damos conta de mundos atraentes e apetecíveis onde as pessoas são felizes, mas também de mundos horriveis e rejeitáveis que as fazem infelizes, assim como o apelo do ser humano a pensar a organização social e as suas finalidades, a problematizar a relação entre o individual e o coletivo, a enfatizar a tensão entre a liberdade e o controle. (ARAÚJO, 2016, p. 10).
\end{abstract}

Utopia e distopia são como os lados de uma mesma moeda, que estampa tanto o projeto moderno de uma sociedade mais justa, organizada em benefício do desenvolvimento coletivo e da felicidade individual, quanto o pesadelo de um mundo caótico, afetado por uma guerra nuclear, pela escassez dos recursos naturais ou pelos efeitos do terrorismo. E se por acaso resolvêssemos jogar cara ou coroa com essa moeda, nós a veríamos cair, nos séculos XVII e XVIII, bem mais do lado luminoso que do outro, enquanto, desde o século XIX, tem-se teimado cada vez mais em repetir o aspecto sombrio da utopia. Assim, o profetismo distópico é um modo de exercitar certa nostalgia utópica.

É nessa chave que podemos compreender $O$ som ao redor, uma narrativa rarefeita e fragmentada sobre o cotidiano de Setúbal, bairro de Boa Viagem, no Recife, onde a aparente harmonia das relações entre as classes é perturbada por uma tensão cada vez mais ruidosa e assustadora, premonitória de uma catástrofe que ao final se cumpre. Construído em dois núcleos narrativos, o filme alterna a história da tradicional família de Francisco, dono de engenho e proprietário de quase toda uma rua do bairro, com a de Bia, dona de casa de classe média perturbada pelo cão de guarda do vizinho que não para de latir. A entrada dos guardas noturnos capitaneados por Clodoaldo polariza a temática da segurança. E é nas mãos de quem mais espera proteção que Francisco morrerá: Clodoaldo vinga-se do assassinato de seu pai matando quem o matou.

A crítica especializada em cinema foi quase unânime em reconhecer no filme o diagnóstico das tensões e contradições de nosso desenvolvimento histórico, que prolongou práticas que vinham desde a Colônia. De maneira pontual, é possível traçar, a partir da pesquisa que se dedicou à análise de 16 textos críticos, três pressupostos que orientam a interpretação mais usual de 0 som ao redor:

1) o filme apresenta uma crítica histórico-sociológica sobre as relações de classe no Brasil; 2) o filme utiliza recursos de gênero, como os provenientes do cinema de horror, para compor o clima de medo e a paranoia que perpassa as situações encenadas, e 3) o caráter inovador do filme, que reitera tanto a tradição moderna de busca do novo quanto valoriza o procedimento mais recente de reapropriação de linguagens consolidadas em contextos ainda não explorados, por meio da mistura de recursos estilísticos de gêneros diferentes. (ALMEIDA; PELEGRINI, 2016, p. 742). 
Entretanto, o aspecto que parece ter seduzido a crítica é o seu conteúdo discursivo-imaginário, que se ateve pouco ao que havia ou poderia haver de único nas personagens e situações retratadas, tomando-as - situações e personagens - como alegorias para a denúncia das contradições da modernização brasileira. Constituem-se exemplos a queixa da verticalização dos bairros, a crítica à falta de segurança e aos procedimentos utilizados para combatê-la (proliferação de câmeras, guardas noturnos etc.), o problema das relações fetichizadas com os objetos etc. Assim, o filme defende a tese de que a modernização do país, do modo como ocorreu, foi incapaz de alterar as estruturas do Brasil colonial que estiveram na base da formação do povo brasileiro, principalmente como estudada por Gilberto Freyre, referência direta no filme, seja por suas fotografias iniciais, pela sequência do engenho ou mesmo por sua dedicatória a Joselice Jucá, historiadora que trabalhou com o sociólogo pernambucano e que é também mãe do cineasta.

Essa alegoria distópica do Brasil é composta artisticamente por meio da repetição de alguns elementos estilísticos ${ }^{3}$ ao longo do filme. Por exemplo, um procedimento recorrente consiste em desenvolver, numa mesma cena, um fragmento do cotidiano e um discurso crítico sobre esse fragmento. Assim, cada cena, ao mesmo tempo em que se conecta com outras para formar um todo, também atua de maneira independente, compondo uma unidade de sentido. Há, então, um entrelaçamento de discursos que ora servem à crônica do cotidiano, ora fazem avançar a narrativa.

A vingança de Clodoaldo é o mote que conduz o filme, evidente apenas em seus momentos finais, mas preparada desde o início, por meio de premonições geradas com a conjunção de efeitos sonoros perturbadores e movimentos de câmera típicos do gênero de suspense e horror. A ambientação tensa é justificada pela revelação final, mas serve também para pontuar o conflito de classes, cada vez mais ruidoso ao longo do filme.

Em paralelo à narrativa, ou em suas brechas, desenvolve-se a crônica cotidiana, esteticamente construída por meio da tensão entre o sensorial e o discursivo. Assim, em meio a uma cena banal, ou mais comumente em sua conclusão, a câmera conduz o olhar do espectador para um lugar não usual, pontuando um comentário visual. 0 efeito é de estranhamento - o que os formalistas russos chamaram de ostranenie e Freud (1976) de unheimlich, isto é, o estranho que surge no seio do que é familiar.

No caso de $O$ som ao redor, o efeito de estranhamento é obtido por um enquadramento de câmera precedido do movimento de zoom aproximativo e pela banda sonora que destaca sons graves, pouco agradáveis e, em alguns casos, extracampo. Tal recurso estilístico é fartamente utilizado em filmes do gênero horror e causa desconforto no espectador, além de uma sensação premonitória. Vemos tais procedimentos desde o início do filme, com o som da serra elétrica, enquadrada por um zoom aproximativo; quando Bia utiliza o aspirador de pó ou faz sexo com a máquina de lavar roupa; no zoom que enquadra o monitor da câmera de segurança no momento em que Clodoaldo chega à casa de Anco; de maneira acintosa, durante a conversa de João com seu avô, quando a câmera por duas vezes abandona o personagem para se fixar numa comunidade próxima,

3 - Aumont (2003, p. 109) entende que "o estilo é a parte de expressão deixada à liberdade de cada um, não diretamente imposto pelas normas, pelas regras de uso. É a maneira de se expressar própria a uma pessoa, a um grupo, a um tipo de discurso. É também o conjunto de caracteres singulares de uma obra de arte, que permitem aproximá-las de outras obras para compará-la ou opô-la". 
enfatizando o contraste social. À medida que o filme avança, o procedimento torna-se mais perturbador, com as cenas do homem caminhando pelo telhado, o pesadelo da filha de Bia, o vulto no corredor e a emblemática sequência de João e Sofia na senzala, no cinema e no banho de cachoeira.

Não surpreende, portanto, que a cena final misture sons de fontes distintas, com os disparos da arma de fogo sobrepondo-se à imagem das bombas da festa junina. A fusão dos sons embaralha também o significado das cenas distintas: a pequena vingança da família contra o cão barulhento tem o mesmo significado simbólico que os tiros que vingam a morte do pai de Clodoaldo.

A frontal simplicidade da trama central compensa-se pela complexa camada de sentidos arrolados nas micronarrativas que compõem a película. E são essas micronarrativas que discursam sobre o panorama contemporâneo do Brasil e sua ligação com o passado. Ivone Rabello (2015, p. 171) faz essa conexão, apontando que a derrota da luta política dos camponeses nas décadas de 1950/60 determinou o "advento do Brasil contemporâneo", com o aprofundamento das desigualdades e dos temores das classes média e alta. Tal cenário é agravado pelo fim das perspectivas de futuro. Sobre o final do filme, a pesquisadora analisa:

A não explicitação sobre os mortos, se é que houve mortos, é decisiva, pois, em qualquer dos casos, nada se resolve estruturalmente: outros cães continuarão a ladrar, outros "coronéis" continuarão a precisar de capangas, outros vingadores retornarão, e a cidade continuará a gerar ruídos confusos e a amortecer os confrontos. Nada se supera ou se aperfeiçoa, a não ser os estratagemas da vingança pessoal, sem poder de mobilização. [...] Sinalizando a amplitude do mal-estar social, a revanche pessoal não engendra estratégias coletivas de luta nem ambiente organizativo. Limita-se às compensações simbólicas, ao pacto de sangue, à justiça selvagem. (RABELLO, 2015, p. 172).

Esse cenário proposto pelo filme, bem como suas implicações, assinala uma visão distópica. E para isso não foi preciso ambientá-lo no futuro, ${ }^{4}$ como o fizeram Cosmópolis, de David Cronenberg, e Holy motors, de Leos Carax (para ficarmos com lançamentos do mesmo ano de 2012). 0 futuro tornou-se tão incerto quanto o presente; a qualquer momento, este pode conduzir ao fim daquele. Assim, ainda mais drásticos que $O$ som ao redor são 4:44 - O fim do mundo, de Abel Ferrara (também de 2012), e Melancholia, de Lars Von Trier (do ano anterior), que trazem para o presente o fim concreto do mundo físico, acrescentando notas niilistas ao tom distópico.

Relacionando o filme aos fundamentos educativos, parecem predominar $o$ cognitivo, o estético e o filosófico nas escolhas estilísticas do cineasta. Há, assim, um investimento cognitivo para persuadir o espectador sobre o que está se passando sob a aparente normalidade do cotidiano, principalmente com as movimentações da câmera. 0 aspecto estético, presente na referida movimentação da câmera, faz-se ainda mais presente

4- Costa (2016, p. 9) também considera a possibilidade de compreender "as visões distópicas como uma realidade alternativa do tempo presente e/ou passado". 
na textura sonora do filme, evidenciada desde o título. E, por fim, o aspecto alegórico funciona como uma síntese filosófica, uma tese, um estudo ou ensaio sobre a situação da sociedade brasileira contemporânea.

Como toda obra distópica, $O$ som ao redor incute uma boa dose de negatividade ao tempo presente, faz dele fonte de temor e infelicidade, e almeja, assim, persuadir-nos sobre a urgência de mudanças e transformações. É aqui que a distopia se distancia radicalmente da utopia, pois, enquanto esta acreditava saber o que e como mudar (projeto moderno), o imaginário distópico silencia sobre as alternativas para o porvir.

\section{O insustentável peso ${ }^{5}$ do niilismo em 0 cavalo de Turim}

O niilismo contemporâneo encontra suas raízes no século XIX, mais especificamente na literatura russa de Turgueniev e Dostoiévski e no diagnóstico de Nietzsche (1983) sobre a morte de Deus e a crise da finalidade, da totalidade e da verdade do mundo metafisicamente idealizado (ALMEIDA, 2015). De lá para cá, é possível notar uma "escalada do niilismo" (GIACOIA JR., 2014, p. 222), cuja "desvalorização dos valores supremos" (VATTIMO, 1996, p. 4) se faz cada vez mais visível na contemporaneidade. De modo geral, os filmes niilistas mostram um esvaziamento, um enfraquecimento do sentido da vida. Nada no mundo tem valor, tudo está em decadência. Adeus Drago Inn (2003), de Tsai Ming Liang, Anticristo (2009) ou Ninfomaniaca (2013), de Lars Von Trier, e Clube da luta (1999), de David Fincher, exemplificam essa visão que reduz a nada o valor da vida.

No entanto, nenhum desses filmes leva o niilismo tão longe quanto $O$ cavalo de Turim (2011), de Béla Tarr, cuja cinematografia se faz conhecer por uma estética ou, mais precisamente, por uma poética muito particular e pungente: imagens em preto e branco de forte contraste, longos planos-sequências, exploração da profundidade de campo, narrativa rarefeita, trilha sonora minimalista, controle preciso da câmera na alternância de movimentos e momentos fixos - enfim, um conjunto de procedimentos estilísticos que não suscitam dúvidas sobre sua importância inventiva na história do cinema, como reconhecem Mark Cousins (2013), Jacques Rancière (2013) e András Kovács (2013). Sua influência é também apontada na obra de cineastas como Gus Van Sant, Pedro Costa e Carlos Reygadas. Há, ainda, numerosas publicações acadêmicas que apresentam estudos e interpretações sobre sua obra, com destaque para Santantango (ou Tango de Satanás), de 1994, e 0 cavalo de Turim.

Tendo como ponto de partida a imagem de um cavalo e a voz do narrador que relata o episódio ocorrido em 3 de janeiro de 1889, quando Friedrich Nietzsche interrompeu um cocheiro que fustigava duramente seu cavalo numa rua de Turim, caindo em seguida na demência que o acompanhará por dez anos até sua morte, $O$ cavalo de Turim estabelece uma conexão simbólica entre o cavalo da perda de lucidez de Nietzsche, "sobre o qual nada se sabe", e o cavalo de Ohlsdorfer, que pressagia o fim do mundo consumado no final do filme.

5- Em entrevista a Oliveira (2012), Béla Tarr assim definiu 0 cavalo de Turim: "Conhece aquele livro que fala da insustentável leveza do ser... 0 meu filme é o contrário, fala do insustentável peso do ser...". 
Dividida em seis dias, a película detém-se nas atividades cotidianas do velho e de sua filha, que lutam em vão para que o cavalo volte a comer e a trabalhar, em meio a uma incessante tempestade de vento. Dia a dia, surgem novos sinais da iminência do fim: no primeiro, Ohlsdorfer deixa de ouvir os cupins; no segundo, o vizinho Bernhard faz um discurso niilista e profético sobre o fim dos tempos; no terceiro, os ciganos passam em caravana e deixam um livro sagrado que vaticina: "a manhã se converterá em noite, a noite acabará”; no quarto, acaba a água do poço; no quinto, já não há mais luz; quando o sexto dia se anuncia, a filha de Ohlsdorfer desiste, ainda que ele a incentive: "coma, temos que comer".

Como se trata de um filme simbolicamente denso, são múltiplas as interpretações que suscita. Carlos Melo Ferreira (2014, p. 53), por exemplo, afirma que "O Cavalo de Turim é o filme da humilhação e da impotência”. Natália Laranjinha (2016, p. 82) vê o filme como um questionamento do "sentido da vida, nomeadamente a de uma vida sem esperança, uma vida reduzida ao nível da sobrevivência e de uma rotina monótona, [em cujo final] há somente o esquecimento e a morte”. Para Rosa Maria Martelo (2015, p. 16), o fim do mundo é um pensamento, uma alegoria, uma tentativa de interromper o devir, expressão do desejo de um novo princípio, razão pela qual, na interpretação da autora, "o facto de dividir o filme em seis dias não pode deixar de nos fazer pensar num sétimo dia em que tudo possa afinal recomeçar”. É a mesma conclusão a que chega Daniel Soares Abib (2016, p. 44): "Tarr reencontra, portanto, um certo renascer de possibilidades, justamente quando se abdica de propor uma direção; quando já não espera que a realidade lhe aponte uma direção".

Jacques Rancière registra a mudança temática e estética na carreira do diretor, que abdicou das contradições da Hungria comunista presentes em seus primeiros filmes para eleger, nos últimos, uma abordagem cósmico-existencial. No caso do filme em análise, Rancière (2013) destaca o aspecto simbólico do cavalo: instrumento de trabalho e meio de sobrevivência, animal mártir dos humanos ao qual Nietzsche se abraçou nas ruas de Turim e, por fim, símbolo da existência do cocheiro inválido e de sua filha, um irmão do camelo nietzschiano, feito para carregar todos os fardos possíveis.

András Kovács (2013, p. 146) reforça essa visão afirmando que o cavalo castigado representa a existência sub-humana mais humilhada, impotente e miserável. 0 encontro do filósofo com o cavalo seria símbolo do colapso mental de Nietzsche, assim como o colapso de Nietzsche funciona como uma premonição do apocalipse. Para Kovács, o fato de a história girar em torno do cavalo que provocou a reação de Nietzsche, e não sobre um cavalo qualquer espancado por seu dono, estabelece uma relação reflexiva, em que a história do cavalo dá ao episódio de Nietzsche um aspecto moral, enquanto tal episódio dá à história do cavalo uma dimensão filosófica.

É possivel afirmar, então, que essa obra fundamenta-se educativamente por seus aspectos predominantemente filosóficos, estéticos, míticos e existenciais. A película encena, de uma maneira muito particular, o mito do fim do mundo, como reconheceu o próprio Béla Tarr (apud MELL0, 2015, p. 9): "Vamos desaparecendo da vida, da terra e então morremos. Isto não é o apocalipse, nem algo ruidoso. É simplesmente a morte”. É uma imagem muito precisa do fim do mundo: o esgotamento das forças físicas e cósmicas, 
as primeiras simbolizadas pelo cavalo, pelo velho e pela mulher, e as segundas pelo vento que deixa de soprar, pela água do poço que seca e pela luz que já não pode ser acesa. Essa é a imagem do fim do mundo, imagem que suscita a reflexão sobre a existência e a passagem do tempo.

0 tempo é um elemento complexo do filme, pois estão concatenados os tempos cíclico (repetições cósmicas) e de rompimento dessa circularidade. Como aponta Kovács (2013), a repetição dos eventos cotidianos não turva a marcha de seis dias rumo ao fim. Para Rancière (2013), o filme articula três tempos: o tempo do declínio, tanto do cavalo quanto das personagens que veem o fim inexorável se aproximando, com o poço seco e o lampião que já não acende; o tempo da mudança, quando intentam partir com a mulher puxando a carroça; e, por fim, o tempo da repetição, da espera atrás da janela de onde se observa, ao longe, a dança das folhas a cair da árvore.

Soma-se ao fim do mundo o fim das próprias narrativas, dado simbólico da perda da capacidade humana para fabular imagens do cosmos, da natureza ou de qualquer outra totalidade. As personagens - com exceção do monólogo pessimista de Bernhard e da fúria festiva dos ciganos - já não usam a voz para expressar sua humanidade. Em contrapartida, há a presença descarnada da voz do narrador, que pontua a narrativa desde o episódio nietzschiano até a persistência do silêncio de morte que marca o final do filme. É um narrador que aparece para nos lembrar que não há mais narrativas. Enquanto os filmes anteriores de Béla Tarr denunciavam o engodo de todas as histórias - pois as histórias todas, contadas desde o Antigo Testamento, não fazem mais que gerar expectativas que se revelam enganosas (RANCIĖRE, 2013) -, O cavalo de Turim reduz-se à espera, quase silenciosa, do fim de todas as esperanças.

Estamos, portanto, diante de uma narrativa niilista de grau avançado, que vai muito além da perda da crença na metafísica ou na religião, na política ou no futuro. A potência máxima do niilismo de Tarr reduz a existência humana às suas condições mais básicas: cavalos cansados incapazes de ultrapassar a condição repetitiva dos atos e gestos da sobrevivência diária. Emudecida a narrativa, perdido o interesse em fabular o mundo, deixamos de ser animais simbólicos (CASSIRER, 1994). E uma vida sem imaginação já não é mais vida. É o fim da humanidade.

\section{A trágica afirmação de Sono de inverno}

Nuri Bilge Ceylan iniciou sua carreira de cineasta na década de 1990, tendo seus filmes desde cedo se destacado em festivais, principalmente em Cannes, onde participou com A pequena cidade (1997), Mayus Sikintisi (1999) e Distante (2002), este recebendo o prêmio do júri e o projetando internacionalmente. Depois vieram Climas (2006), Três macacos (2008) e Era uma vez na Anatólia (2011), todos premiados, até que Ceylan ganhou a Palma de Ouro, em 2014, com Sono de inverno.

Seus filmes não se preocupam com grandes acontecimentos, mas com os pequenos sofrimentos e prazeres do cotidiano, narrados de maneira complacente, sem juízos de valor moral, religioso ou de qualquer outra ordem. Não é possível dizer que seus filmes sejam pessimistas, pois, ao fınal, sem resvalar em uma solução positiva, terminam por afirmar a 
vida, com todos os sofrimentos e sem a esperança de ultrapassá-los. Distante (2002), por exemplo, narra o aumento progressivo da distância entre Mahmut e Yusuf, terminando com um gesto simbólico de aproximação justamente no momento de rompimento defınitivo. Ambos sabem que a distância é inevitável e que a solidão que a acompanha é incontornável, mas, ao aceitarem que assim o seja, estão de algum modo juntos.

Tal fórmula - presente também nas demais películas do cineasta turco - pode ser defınida como trágica: "fórmula da afırmação máxima, da plenitude, da abundância, um dizer sim sem reservas, até mesmo ao sofrimento, à própria culpa, a tudo o que é problemático e estranho na existência” (NIETZSCHE, 1995, p. 118). Esse imaginário da afırmação não é simples de ser reconhecido, pois, em determinado grau, quase todos os filmes de ficção, de um lado, tocam o sofrimento e, de outro, garantem alguma dose de aprovação. A questão fundamental do imaginário trágico é a ausência de justificativa para o sofrimento; o reconhecimento do acaso primordial; a ausência de princípio, objetivo ou finalidade da existência; o caráter egoísta da vontade e seu desejo de potência; a efemeridade inerente à condição humana; a ausência de sentido referencial exterior à própria existência - enfım, o conjunto dos traços que demarcam a tragicidade da vida, mas com a exigência incontornável de que seja acompanhada de sua afırmação incondicional.

Os filmes de Woody Allen podem ser compreendidos como afirmativos, principalmente Match point (2005) e Meia-noite em Paris (2011) (ALMEIDA, 2012). A grande beleza (2013) e Juventude (2015), de Paolo Sorrentino, também podem ser considerados afirmativos, assim como $O$ intrépido (2013), de Gianni Amelio, e A febre do rato (2011), de Cláudio Assis. A seu modo, cada um desses filmes apresenta a vida como um valor que não pode ser avaliado a não ser pela própria vida, afirmando-a num registro que se filia ao amor fati nietzschiano: "não querer nada de outro modo, nem para diante, nem para trás, nem em toda a eternidade. Não meramente suportar o necessário, e menos ainda dissimulá-lo [...], mas amá-lo" (NIETZSCHE, 1983, p. 374).

Sono de inverno (2014) tem como título original Kis Uykusu, cuja tradução literal é hibernação. Foi internacionalmente rebatizado como Winter sleep, perdendo em parte a força da metáfora, que se aplica bem à inação dos protagonistas, principalmente quando chega o inverno e se veem abrigados num confortável hotel da Capadócia, na Anatólia, mas sem poder escapar das animosidades do outro com quem convivem. Denso e com mais de três horas de duração, o filme explora a dimensão interior dessas personagens, suas relações sociais e amorosas, além de seus posicionamentos filosóficos perante a vida. Baseada em contos de Tchekhov (2007), a narrativa desenvolve-se lentamente, permeada mais por diálogos que por acontecimentos, e centra-se na relação de Aydin com sua mulher Nihal, sua irmã Necla, seus empregados, um amigo e uma família de inquilinos de um de seus imóveis. Essas situações são exploradas para discutir temas como poder, moral, religião, caridade, amor e maldade, em uma perspectiva filosófica.

A crítica especializada registra as qualidades estilístico-estéticas do filme e a profundidade da investigação sobre a condição humana. Embora haja uma ou outra ressalva quanto ao ritmo e à duração da película, o reconhecimento da beleza da fotografia e de sua qualidade cinematográfica como um todo é consenso. 0 estilo de filmar do diretor costuma ser caracterizado como clássico, com uso de planos fixos harmonizados 
com deslocamentos panorâmicos da câmera, bem como valorização da paisagem natural, que tende a apequenar o homem nela inserido, além de assegurar um registro realista que contribui para a densidade psicológica do drama. Não há uma narrativa complexa nem quebra de linearidade na exposição da trama, cuja simplicidade contribui para a complexidade dos diálogos.

Christophe Brangé (Abus de Ciné) (2014) assinala a "precisão cirúrgica" com a qual o cineasta desenha o retrato de um homem "cínico, arrogante", em uma película de "experimentação cinematográfica" que mistura poesia e uma "profunda reflexão sobre a natureza humana”. Ressaltando o caráter poético de Sono de inverno, Ángel Luis Inurria (Cine para Leer) (2014) sublinha "o aroma da melancolia perfumando o tédio que envolve a paisagem de Tchekhov, aqui transladada por Nuri Bilge Ceylan ao inverno da nevada Capadócia de hoje”. Inurria aponta a crise da tradição e dos valores, o fantasma da precariedade, as inalcançáveis ilusões que desembocam no fracasso, a aceitação da dor e a reconhecida má consciência como elementos centrais do filme. Carlos Fernández Castro (Bandeja de Plata) (2014) enfatiza o caráter predominantemente particular da narrativa, a qual qualifica como "magnífico estudo psicológico do comportamento humano", destacando a profundidade dos diálogos, seu sentido de ritmo e a simplicidade de um cinema que vai buscar na realidade a matéria-prima para um tratamento universal da condição humana. 0 crítico interpreta a obra como a transmissão da "ideia de que o dinheiro não garante a felicidade e que a dignidade não tem preço”. Compondo o mosaico crítico, Chiara Guida (Cinefilos) (2014), ainda que se ressinta da duração do filme e da repetição de certas situações, enaltece sua beleza poética, que parece querer dissecar todo o mal do mundo. Por fim, CS e PP (Fitas Duplas) (2014) ressaltam a beleza visual do filme e a hibernação dos personagens, que se acostumam lentamente a "não viver, adormecidos pelo conforto, pela falta de ter para onde ir, pela necessidade de calor ou simplesmente porque mudar já não parece uma opção". A dupla também reconhece que o filme trata da criação de ilusões como uma característica intrínseca do humano.

Os aspectos apontados pela crítica, ainda que insuficientes para penetrar na imagem de mundo que o filme propõe, reconhecem que sua poética está centrada na paisagem, na inconstância das relações humanas e na densidade dos diálogos, que, ao escapar do trivial, resvalam ora em debates filosóficos, ora em embates psicológicos, sem, entretanto, resultarem em ações.

Do ponto de vista estilístico-cinematográfico, ressalta-se a estratégia de adaptação dos contos de Tchekhov (2007) que inspiraram o filme, principalmente Minha mulher e Pessoas excelentes, cujos diálogos foram transcritos quase em sua integralidade, mas com deslocamento do contexto geográfico, temporal e narrativo, incidindo em inversões de sentido, como a que ocorre com a adaptação de Pessoas excelentes, que retém deste o diálogo entre os irmãos sobre a não resistência ao mal, mas em um contexto cujo sentido é alterado em favor de Aydin. Assim, no conto, a irmã zomba da pretensão de literato do protagonista e desmascara sua incapacidade intelectual ao propor o debate sobre a não resistência ao mal. 0 filme inverte a pretensão do protagonista, que não almeja nada além de prosseguir escrevendo para o pequeno e inexpressivo jornal local, para incômodo de sua irmã Necla, que ambicionava mais. Em relação ao tema da resistência ao mal, o 
diálogo mantém-se praticamente intacto, mas, no filme, é Aydin quem vence a irmã, que aventa a hipótese de que a não resistência ao mal poderia levar o agressor a se arrepender de seus atos e mudar de atitude. Ao longo do filme, observa-se que tal hipótese jamais passou de uma crença ilusória de Necla, que desejava reatar seu casamento, perdoando as agressões físicas do ex-marido alcóolico.

Esse mesmo tema também é aproveitado para desnudar a ilusão de Nihal, que testemunhará a ingratidão irascível de Ismail, um ex-presidiário alcóolico e inadimplente que reside com a família em uma propriedade de seu marido Aydin. Ao receber uma grande soma de dinheiro doado por ela, Ismail entende o gesto como uma humilhação e queima toda a fortuna na lareira, para desespero de Nihal, forçada a ver sua ilusão de diminuir o sofrimento dos mais fracos tornar-se cinza.

A relação entre Aydin e Nihal baseou-se no conto Minha mulher, que empresta muitos diálogos ao filme, além da trama central, pautada na incapacidade de solução para o dilema do casal. Escravizados um ao outro, nem ele nem ela conseguem partir, embora uma reconciliação seja consensualmente impossível. Entretanto, no conto, o desfecho é pessimista, com a certeza do protagonista de que o assistencialismo desenfreado da esposa os conduzirá à ruína financeira, enquanto, no filme, o final é trágico, pois Aydin sabe que não há como afirmar o amor sem afirmar também a dor. Em vez de se dirigir a Nihal - e qualquer palavra seria incapaz de demover seu desprezo por ele -, Aydin confessa, em uma espécie de monólogo interior, não se arrepender de nada, reafirmando seu orgulho e a manutenção de sua vontade. A cena é visualmente poética. Ouvimos a voz de Aydin enquanto vemos sua imagem, primeiro à entrada de casa, olhando para a janela do andar superior onde Nihal chora, depois pela perspectiva de Nihal, em um jogo de alternância de câmeras, que aproxima e afasta simultaneamente o casal. Sua palavra final - "perdoe-me" - indica tanto o reconhecimento de que sua decisão causa sofrimento a Nihal quanto sua incapacidade de poupá-la desse sofrimento. Egoísta, Aydin faz valer sua vontade, confirmando a metáfora da hibernação presente no título: tudo permanece como antes.

Sono de inverno pode ser compreendido como um estudo psicológico da vontade ou um ensaio filosófico sobre a ilusão, filme de caráter vitalista que procura dissecar como o exercício da potência intensifica ou adormece a vontade. Sua inclinação afirmativa faz-se presente, sobretudo, pela aprovação da vida tal como se apresenta, principalmente por parte de Aydin, que, na cena final, após seu retorno a seu refúgio, digita na tela do computador o título do livro que pretende escrever: História do teatro turco, expressão simbólica de seu amor fati, confirmação de que não deseja, mesmo com todo o sofrimento que a acompanha, outra vida.

\section{Considerações finais}

É importante advertir que o presente estudo não pretendeu mapear os discursos cinematográficos contemporâneos lato sensu, entre os quais possivelmente se situaria uma gama diversificada de inclinações, como a cínica, a pragmática, a escapista etc. 0 enfoque recaiu sobre a pressão pedagógica de três forças imaginário-discursivas presentes em filmes que projetam, sob a perspectiva hermenêutico-simbólica, uma proposição de mundo em diálogo com o contemporâneo. 
A análise dos filmes selecionados permite o cotejo de três discursos contemporâneos distintos entre si, mas não sem contato um com o outro. Assim, a distopia de $O$ som ao redor é resvalada por certo grau de niilismo latente na descrença quanto a alternativas para a organização social dos grandes centros urbanos; a violência e o pânico que a acompanha, somados à estética emprestada dos filmes de horror, esboçam uma imagem crítica e negativa do mundo contemporâneo, embora a força das pinceladas sugira a esperança de uma reversão utópica, contraface das denúncias distópicas.

0 pesado e insustentável niilismo de $O$ cavalo de Turim reduz o humano a seus impulsos básicos de sobrevivência e aniquila não só as crenças metafísicas, religiosas e ideológicas sobre o mundo, como o próprio mundo, que silencia e se apaga, num cenário de devastação que se confunde com os piores pesadelos distópicos. Ainda assim, o imaginário niilista faz-se acompanhar de certo grau de afirmação, principalmente do velho Ohlsdorfer, que mesmo diante do fim não perde sua vontade de viver. De outra parte, o investimento poético na beleza, na altivez e na intensidade expressiva da música e da fotografia insta a supor que a afirmação se desloca da narrativa para o estilo, isto é, deixa de vigorar na imagem de mundo (negativa, niilista) e migra para o processo de construção dessa imagem (estética da afırmação).

Em contrapartida, a frágil afirmação de Sono de inverno, restrita ao protagonista, não esconde os degraus niilistas que escalou e que permanecem na incapacidade das demais personagens de escapar à hibernação. Na dinâmica das vontades, apenas a de Aydin se afırma, e não sem cinismo, já que o amor fati que o caracteriza não se dissocia do poder que exerce e do sofrimento que, quando não testemunha, atiça. Mas o filme isenta-se de qualquer juízo moral, investindo num vitalismo para além do bem e do mal que intensifica o imaginário trágico e tinge a imagem do mundo de cores afırmativas.

Fundamentadamente educativo, o cinema opera a mediação - cognitiva, estética, filosófica, mítica, existencial, antropológica e poética (ALMEIDA, 2017) - entre os homens e o mundo, pondo em circulação forças imaginário-discursivas que denotam um contemporâneo multifacetado, produtor e produto de proposições de mundo que circulam culturalmente e exercem pressão pedagógica no modo como o vemos e nos vemos nele. Os três imaginários estudados - da distopia, do niilismo e da afirmação -, longe de esgotar as possibilidades de pleito por uma imagem dominante de mundo, sinalizam sua débil e insólita deriva.

\section{Referências}

ABIB, Daniel Soares. Narrativa niilista: um olhar narrativo sobre "0 cavalo de Turim". Rascunho: Monografias Cinema e Vídeo, Niterói, v. 8, n. 13, 2016.

ALMEIDA, Rogério de. "Meia-noite em Paris". In: ALMEIDA, Rogério de; FERREIRA SANTOS, Marcos (Org.). Cinema e contemporaneidade. São Paulo: Képos, 2012. p. 39-52.

ALMEIDA, Rogério de. Possibilidades formativas do cinema. Rebeca: Revista Brasileira de Estudos de Cinema e Audiovisual, v. 6, jul./dez. 2014. 
ALMEIDA, Rogério de. Antiniilismo: ou a superação do niilismo pela filosofia trágica. Revista de Estudos de Cultura, São Cristóvão, n. 3, p. 75-83, 2015.

ALMEIDA, Rogério de. Cinema e educação: fundamentos e perspectivas. Educação em Revista, Belo Horizonte, v. 33, p. 1-27, 2017.

ALMEIDA, Rogério de; PELEGRINI, Christian H. Os textos críticos sobre o filme 0 Som ao redor, seus pressupostos estéticos e desdobramentos hermenêuticos. Palabra Clave, Chía, v. 19, p. 721-745, 2016.

ARAÚJJ, Joaquim Machado de. Felicidade e liberdade: para uma utopia do humano. Vila Nova de Gaia: Fundação Manuel Leão, 2016.

AUMONT, Jacques. Dicionário teórico e crítico de cinema. Campinas: Papirus, 2003.

BACHELARD, Gaston. La poétique de la rêverie. 5. ed. Paris: PUF, 1971.

BADIOU, Alain. El cine como experimentación filosófica. In: YOEL, Geraldo (Org.). Pensar el cine 1: imagen, ética y filosofía. Buenos Aires: Manantial, 2004.

BENITEZ, Roberto Sánchez. La recuperación de lo trágico: música y humanismo. Monterrey: Cecyte, N. L.-CAEIP, 2012.

BORDWELL, David. La narración en el cine de ficción. Barcelona; Buenos Aires; México, DF: Paidós, 1996.

BRANGÉ, Christophe. Exercice de style brillamment mis en scène. Abus de Ciné. 2014. Disponível em: <http://www.abusdecine.com/critique/winter-sleep>. Acesso em: 28 out. 16.

CABRERA, Julio. 0 cinema pensa: uma introdução à filosofia através dos filmes. Rio de Janeiro: Rocco, 2006.

CAMPBELL, Joseph. As máscaras de Deus: mitologia primitiva. São Paulo: Palas Athena, 2010.

CASSIRER, Ernst. Ensaio sobre o homem: introdução a uma filosofia da cultura humana. São Paulo: Martins Fontes, 1994.

CASTRO, Carlos Fernández. Sueño de invierno (Kis Uykusu) (2014). Bandeja de Plata, 2014. Disponível em: $<$ http://www.bandejadeplata.com/criticas-de-cine/sueno-de-invierno-kis-uykusu-2014/>. Acesso em: 28 out. 16.

CAVALO de Turim, 0. Diretor: Béla Tarr. Produção: TT Filmmûhely, Vega Film, Zero Fiction Film. Hungria, França, Alemanha, Suíça, USA, 2011. 146 min.

COSTA, Maria Helena B. V. Paisagens urbanas e lugares utópicos no cinema brasileiro. In: COLOQUIO INTERNACIONAL DE GEOCRÍTICA LAS UTOPÍAS Y LA CONSTRUCCIÓN DE LA SOCIEDAD DEL FUTURO, 14., 2016, Barcelona. Anais... Barcelona: UB, 2016. p. 1-17. 
COUSINS, Mark. História do cinema: dos clássicos mudos ao cinema moderno. São Paulo: Martins Fontes, 2013. CS; PP. Após a bonança. Fitas Duplas (blog), 2014. Disponível em: <http://fitasduplas.blogspot.pt/2014/11/ apos-bonanca.html?spref=pi>. Acesso em: 28 out. 2016.

DELEUZE, Gilles. Cinema: imagem-movimento. São Paulo: Brasiliense, 1985.

DURAND, Gilbert. Mito, símbolo e mitodologia. Lisboa: Presença, 1981.

DURAND, Gilbert. As estruturas antropológicas do imaginário. São Paulo: Martins Fontes, 1997.

FAVARETTO, Celso F. Deslocamentos: entre a arte e a vida. ARS, São Paulo, v. 9, p. 94-109, 2011.

FERREIRA, Carlos Melo. Sobre dois filme de Béla Tarr. In: ENCONTRO ANUAL DA AIM, 3., 2014, Coimbra. Atas... Coimbra: AlM, 2014. p. 48-57.

FREUD, Sigmund. 0 estranho. In: FREUD, Sigmund. Edição standard brasileira das obras completas. v. 17. Rio de Janeiro: Imago, 1976. p. 271-318.

GIACOIA JR., Oswaldo. Nietzsche: o humano como memória e como promessa. Petrópolis: Vozes, 2014.

GUIDA, Chiara. I Regno d'Inverno recensione del film di Nuri Bige Ceylan. Cinefilos, 2014. Disponível em: <http://www.cinefilos.it/tutto-film/recensioni/regno-dinverno-recensione-film-nuri-bilgeceylan-162965>. Acesso em: 28 out. 16.

INURRIA, Ángel Luis. Winter Sleep (Sueño de Invierno). Cine para Leer, 2014. Disponível em: <http://www. cineparaleer.com/critica/item/1598-winter-sleep-sueno-de-invierno>. Acesso em: 28 out. 16.

KOVÁCS, András. The cinema of Béla Tarr: the circle closes. New York: Columbia University Press, 2013.

LARANJINHA, Natália. 0 fim do mundo em Lars Von Trier, Abel Ferrara e Béla Tarr. Revista Livre de Cinema, v. 3, n. 2, p. 72-83, 2016.

MARTELO, Rosa Maria. Fim do mundo / Reiniciar. Elyra: Revista da Rede Internacional Lyracompoetics, Porto, n. 5, p. 9-19, 2015.

MELLO, Lídia. Béla Tarr, o cineasta do tempo e do cotidiano. Rebeca: Revista Brasileira de Estudos de Cinema e Audiovisual, v. 4, jul./dez. 2015.

MERLEAU-PONTY, Maurice. 0 cinema e a nova psicologia. In: XAVIER, Ismail (Org.). A experiência do cinema. Rio de Janeiro: Graal, 1983. p. 101-117.

MORIN, Edgar. 0 cinema ou o homem imaginário: ensaio de antropologia sociológica. São Paulo: É Realizações, 2014. 
NIETZSCHE, Friedrich. Obras incompletas. São Paulo: Abril Cultural, 1983. (Os pensadores).

NIETZSCHE, Friedrich. Ecce homo: como alguém se torna o que é. São Paulo: Companhia das Letras, 1995.

OLIVEIRA, Luís Miguel. Béla Tarr, o insustentável peso do ser. Público, Lisboa, 14 jun. 2012. Disponível em:<https://www.publico.pt/2012/06/14/culturaipsilon/noticia/bela-tarr-o-insustentavel-peso-doser-306369>. Acesso em: 15 dez. 2016.

RABELLO, Ivone Daré. 0 som ao redor: sem futuro, só revanche? Novos estudos Cebrap, São Paulo, n. 101, p. 157-173, mar. 2015.

RANCIÈRE, Jacques. Después del final. Buenos Aires: El Cuenco de Plata, 2013.

RICOUER, Paul. Hermenêutica e ideologias. Petrópolis: Vozes, 2008.

ROSSET, Clément. Reflexiones sobre cine. Buenos Aires: El cuenco de Plata, 2010.

SOM ao redor, 0. Direção: Kleber Mendonça Filho. Produção: Emilie Lesclaux. Recife: CinemaScópio, 2012. $131 \mathrm{~min}$.

SONO de inverno. Direção: Nuri Bilge Ceylan. Produção: Zeynofilm, Bredok Filmproduction, Memento Films Production. Turquia, Alemanha, França, 2014. 196 min.

SPINOZA, Baruch. Ética. Belo Horizonte: Autêntica, 2009.

TCHEKHOV, Anton. Contos de Tchekhov. Lisboa: Relógio D’Água, 2007.

VATTIMO, Gianni. 0 fim da modernidade: niilismo e hermenêutica na cultura pós-moderna. São Paulo: Martins Fontes, 1996.

Recebido em: 28.01.2017

Aprovado em: 25.05.2017

Rogério de Almeida é professor associado da Faculdade de Educação da Universidade de São Paulo (FEUSP). Coordena o Lab_Arte e o GEIFEC. É bacharel em Letras (1997), doutor em Educação (2005) e livre-docente em cultura e educação, todos os títulos pela Universidade de São Paulo (USP). Realizou pós-doutoramento na Universidade do Minho (2016). Trabalha com temas ligados a cinema, literatura, filosofia trágica e imaginário. Website: www.rogerioa.com. 